\title{
ENHANCING THE SALES PROCESS USING ANALYTIC NETWORK PROCESS
}

\author{
Fariborz Y. Partovi \\ Department of Decision Sciences \\ Drexel University Philadelphia PA, USA \\ E-mail Partovi@ Drexel.edu \\ Cynthia A. Conway, \\ Department of Marketing \\ Drexel University Philadelphia PA, USA \\ E-mail Conway@ Drexel.edu
}

\begin{abstract}
In 2010, a leading wealth management firm set a milestone to be recognized as the provider of choice for comprehensive, multigenerational wealth management services in the US by 2015. In 2010, the firm was ranked $15^{\text {th }}$. Using the Strategic Service Vision (SSV) and Analytic Network Process (ANP) methodologies, they leveraged their strategic thinking to improve their sales process, and determine which project initiatives provided the highest ability to increase sales.
\end{abstract}

Keywords : analytic network process, strategic project selection, process improvement projects 


\section{Introduction}

This leading wealth management firm, founded in 1903, has consistently been at the forefront of their industry with innovative ways to meet and exceed the needs of high net worth individuals and their families. By 2010, it had grown to serve clients in all 50 states and 22 other countries. Having enjoyed a leadership role of being one of the largest personal trust providers in the United States, it was eager to establish that same prestige as a comprehensive wealth manager in the minds of the marketplace, offering trust, investment management and family office services. To accomplish this, the firm set a 2015 goal to be recognized as the provider of choice for comprehensive, multigenerational wealth management services in the United States versus the $15^{\text {th }}$ position it held.

Many initiatives were identified to ensure this goal was met. One of these initiatives included the development of a business design and value proposition to help the organization break out from beneath the "sea of sameness" within the industry. As a result of this work, a communications platform entitled, Peace of Mind was created. The leadership team decided to implement it throughout the marketing, sales and service areas of the organization as a means to establish a consistent way to promote the company and enhance "the client experience". It was believed that consistent messaging, grounded on the "wants" of the high net worth individuals would enable the staff to better articulate "the firm's story" to current and future clients. The main question the company was addressing was: Which potential initiatives will provide them with the highest ability to increase sales? In this paper we will use the combination of ANP (Saaty, 2013) and SSV (Heskett, Sasser, and Hart 1990) to determine which project is more effective.

\section{Literature Review}

The use of the ANP in strategically evaluating the project selection process has received considerable attention in recent literature. For example, the ANP model was used by Begicevic et al. (2010) to show how to include corporate strategy in prioritizing projects in higher education institutions. It was also used by Meade and Sarkis (1998), for strategic selection of logistics, and by Kornfeld and Kara (2011) who suggested a systematic approach to project portfolio selection in continuous improvement setting. Lastly, Meade and Presley (2002), used the ANP for project selections based on research and development. However in order to maintain competitive advantage, companies need to have and manage successful projects that are strategically sound and hard to imitate. Various critical factors, such as customers "wants" and process enablers have not been systematically investigated in the previous studies. The purpose of this paper is to bridge this gap by providing valuable insights into strategic process improvement projects by using the ANP framework.

\section{Methodology}

The approach we used in this research was to utilize a framework combining Heskett's et al. (1990) Strategic Service Vision (SSV) concept with Saaty's (2013) Analytic Network Process (ANP). The SSV/ANP combination was an ideal approach to answer the above question. It is specifically designed to identify key customers" "wants" and relate them to front and back room activities that are involved in service delivery process. Once the important activities are identified, they can be categorized, based on importance and their relationship to key client wants. Finally which projects complements the communication platform and drive increased sales?

Figure 1 shows the basic structure of the model. This network consists of 4 clusters and nodes contained within the clusters. As most ANP networks, the elements within the clusters are connected to the elements in other clusters (outer dependence). Additionally, the elements in some clusters are also influenced by the elements in their own cluster (Inner dependence). Priorities in a network are established in the same way as in the Analytic Hierarchy Process, using pairwise comparisons.

\section{Model Analysis}

The ANP model is designed to tie product offerings and service initiatives directly to client "wants." Primary customer cluster shows that high net worth individuals primarily look for the following qualities in 
choosing among wealth management firms: a stable company, a trusted advisor, premier client service and high ethical standards. Based on ANP calculations, it was determined that these wants are most directly impacted by the following key processes in the sales cycle: learning about firm capabilities, leading the team, and presenting wealth management strategies. Therefore, initiatives most closely aligned with client wants, are the Advisor Training, and the Financial Planning Process.

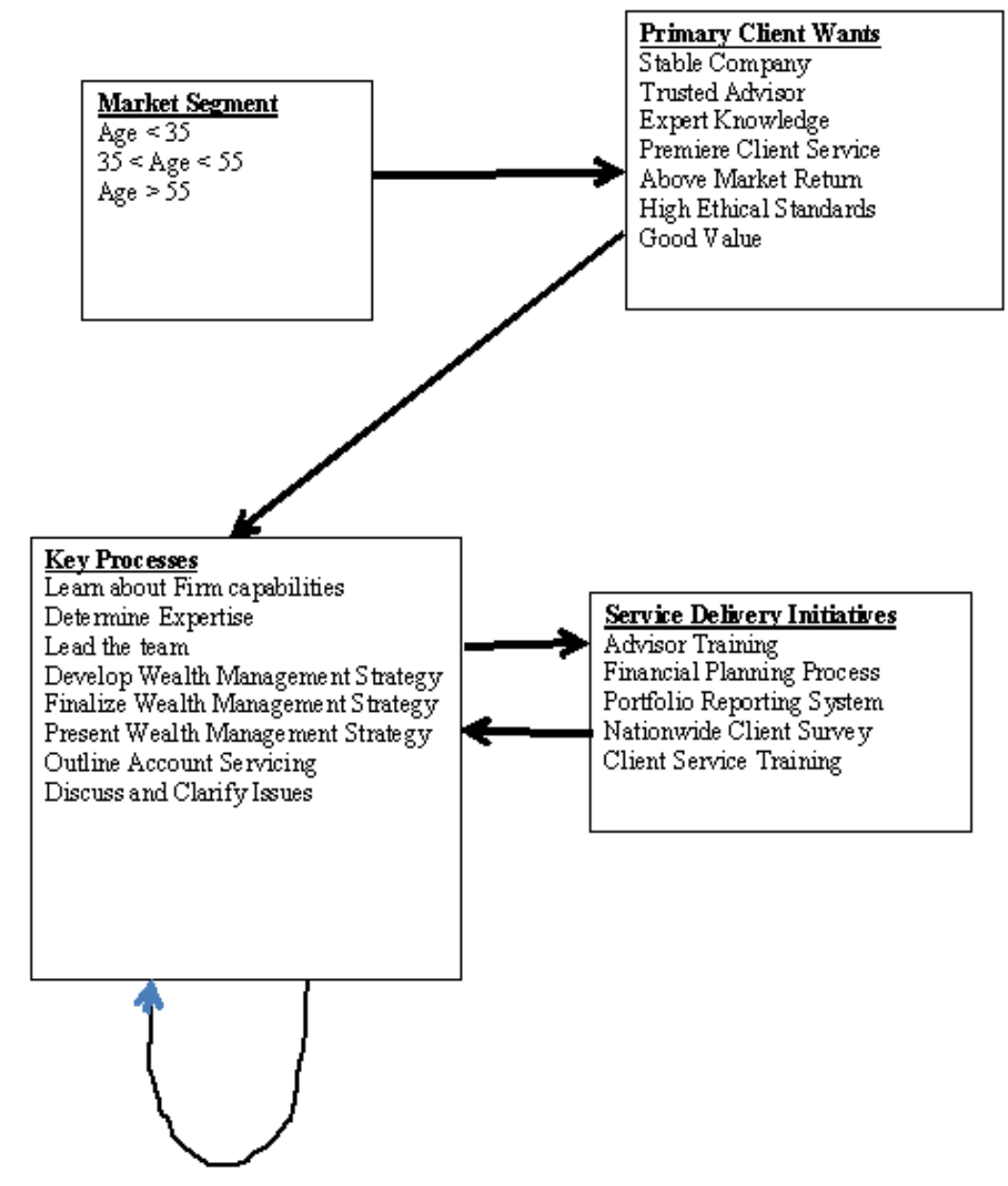

\section{Conclusion}

The methodology introduced in this research, helped to identify eight important activities within the Firm's wealth advisory sales process to fully leverage the communications platform Peace of Mind. The recommendation to develop primary messaging to substantiate how each of these key processes is unique to the Firm was approved for implementation in 2013. The recommendation to put these differentiating processes into action via staff training, and highlighting the Firm "back office" processes in marketing and sales materials ( without giving away the operational strategy) was also approved. The SSV/ANP process was an effective means of assessing key client wants and service delivery processes. It enabled senior leadership to select four specific initiatives that would have the most direct impact on the sales process. The final step, a validation meeting with key company representatives, was also extremely helpful. This valuable input allowed modification of one of the recommendations and gain assurance that all of our recommendations were consistent with the long term goals of the Firm. 


\section{Key References}

Saaty, T. L. (2013) The Modern Science of Multi-criteria Decision Making and Its Practical Applications: The AHP/ANP Approach. Operations Research 61(5), 1101-1118.

Heskett, J.L., C, C.W.L. (1990), Service Breakthrough: Changing the Rules of the Game, The Free Press, New York, NY.

Begicevic, N., Divjak, B., \& Hunjak, T (2010). Decision-making on prioritization of projects in higher education institutions using analytic network process approach. Central European Journal of Operations Research 18(3), 341-364.

Meade, L. \& Sarkis, J. (1998) Strategic analysis of logistics and supply chain management system using analytic network process. Transportation Research Part E: Logistic and Transportation Review 34(3), 201-215.

Kornfeld, B. J., \& Kara, S. (2011). Project portfolio selection in continuous improvement. International Journal of Operations \& Production Management 31(10), 1071-1088.

Meade, L. \& Presley A,. (2002). R\&D Project Selection using the Analytic Network Process. IEEE Transactions on Engineering Management, 49(1), 59-66. 